Published in final edited form as:

Biochemistry. 2007 March 20; 46(11): 3234-3245. doi:10.1021/bi062299p.

\title{
STRUCTURE OF THE TYPE III PANTOTHENATE KINASE FROM Bacillus anthracis AT 2.0 A RESOLUTION: IMPLICATIONS FOR COENZYME A-DEPENDENT REDOX BIOLOGY†,,‡
}

\begin{abstract}
Nathan I. Nicely $\S, \|$, Derek Parsonage $§$, Carleitta Paige $§$, Gerald L. Newton ${ }^{\perp}$, Robert C. Fahey $^{\perp}$, Roberta Leonardi\#, Suzanne Jackowski\#, T. Conn Mallett $§, \Delta$, and Al Claiborne ${ }^{*}, \S$ Center for Structural Biology, Wake Forest University School of Medicine, Winston-Salem, North Carolina 27157, Department of Chemistry and Biochemistry, University of California, San Diego, La Jolla, California 92093-0314, and Department of Infectious Diseases, St. Jude Children's Research Hospital, Memphis, Tennessee 38105
\end{abstract}

$\S$ Wake Forest University School of Medicine.

\|Present address: Renaissance Computing Institute, Chapel Hill, North Carolina 27517.

$\perp$ University of California, San Diego.

\#St. Jude Children's Research Hospital.

$\triangle$ Present address: Rigaku, Sevenoaks, Kent, TN15 6QY, England.

\section{Abstract}

Coenzyme A (CoASH) is the major low-molecular weight thiol in Staphylococcus aureus and a number of other bacteria; the crystal structure of the $S$. aureus coenzyme A-disulfide reductase (CoADR), which maintains the reduced intracellular state of CoASH, has recently been reported [Mallett, T.C., Wallen, J.R., Karplus, P.A., Sakai, H., Tsukihara, T., and Claiborne, A. (2006) Biochemistry 45, 11278-11289]. In this report we demonstrate that CoASH is the major thiol in Bacillus anthracis; a bioinformatics analysis indicates that three of the four proteins responsible for

\footnotetext{
${ }^{\dagger}$ This work was supported by National Institutes of Health (NIH) Grants GM-35394 (A.C), AI-49174 (R.C.F.), and GM-62896 (S.J.), by a grant from the Southeast Regional Center of Excellence for Biodefense and Emerging Infections (SERCEB, to A.C.), and by Cancer Center (CORE) Support Grant CA21765 and ALSAC (S.J.). C.P. was the recipient of a Graduate Fellowship from the U.S. Department of Homeland Security (DHS). SERCEB is supported by an award from the NIH (National Institute of Allergy and Infectious Diseases; NIAID). The DHS Scholarship and Fellowship Program is administered by the Oak Ridge Institute for Science and Education (ORISE) through an interagency agreement with the U.S. Department of Energy (DOE). ORISE is managed by Oak Ridge Associated Universities under DOE contract number DE-AC05-06OR23100. The findings, opinions, and recommendations expressed in this paper are those of the authors and are not necessarily those of NIAID, SERCEB, NIH, DHS, DOE, or ORISE. Data for this study were measured at beamline $\mathrm{X} 12 \mathrm{C}$ of the National Synchrotron Light Source. Financial support comes principally from the Offices of Biological and Environmental Research and of Basic Energy Sciences of the DOE, and from the National Center for Research Resources of the NIH.

\$Coordinates have been deposited with the Protein Data Bank under the file name 2H3G.

* To whom correspondence should be addressed. Tel.: (336) 716-3914; Fax: (336) 777-3242 E-mail: alc@csb.wfu.edu

${ }^{2}$ The bacterial and eukaryotic pantothenate kinases have traditionally been distinguished as the CoaA and PanK proteins, respectively. With the identification of two distinct new bacterial pantothenate kinase classes in 2005, different investigators have used either type I, -II, and -III CoaAs (e.g., type II Staphylococcus aureus CoaA) or PanK-I, -II, and -III nomenclature to identify the three bacterial enzyme classes. In this report we refer to the three bacterial enzyme classes as bacterial type I, type II, and type III PanKs; CoaA is synonymous with the type I PanK

5J. Ravel, personal communication.

${ }^{7}$ J.R. Wallen and A. Claiborne, unpublished experiments.

Supporting Information Available A figure depicting a structure-based alignment of 13 type III PanK sequences (Figure S1) is included as Supporting Information (one page). This material is available free of charge via the Internet at http://pubs.acs.org
} 
the conversion of pantothenate (Pan) to CoASH in Escherichia coli are conserved in B. anthracis. In contrast, a novel type III pantothenate kinase (PanK) catalyzes the first committed step in the biosynthetic pathway in B. anthracis; unlike the E. coli type I PanK, this enzyme is not subject to feedback inhibition by CoASH. The crystal structure of B. anthracis PanK (BaPanK), solved using multiwavelength anomalous dispersion data and refined at a resolution of $2.0 \AA$, demonstrates that $B a \mathrm{PanK}$ is a new member of the Acetate and Sugar Kinase/Hsc70/Actin (ASKHA) superfamily. The Pan and ATP substrates have been modeled into the active-site cleft; in addition to providing a clear rationale for the absence of CoASH inhibition, analysis of the Pan-binding pocket has led to the development of two new structure-based motifs (the PAN and INTERFACE motifs). Our analyses also suggest that the type III PanK in the spore-forming $B$. anthracis plays an essential role in the novel thiol/disulfide redox biology of this category A biodefense pathogen.

CoASH has been classified as a "common" thiol (1), as it occurs in all prokaryotes as well as eukaryotes. Although GSH plays the central role in maintaining thiol/disulfide homeostasis and providing an important line of antioxidant defense in, for example, Escherichia coli (2), GSH is clearly absent in a number of bacteria $(3,4)$ as well as all archaea $(5,6)$. CoASH has been shown to be the major low-molecular weight thiol in the human pathogens Staphylococcus aureus (7) and Borrelia burgdorferi (8), in the spore-forming Bacillus megaterium (4) and the radiation-resistant Deinococcus radiodurans (3), and in the hyperthermophile Pyrococcus furiosus (6) and other archaea. Coenzyme A-disulfide reductases (CoADR) ${ }^{1}$ have been characterized in most of these prokaryotes (4,7-9), reinforcing the concept that CoASH assumes the intracellular redox function of GSH in these organisms, and the crystal structure of the $S$. aureus CoADR has recently been reported (10).

In E. coli, pantothenate kinase (CoaA, or type I PanK) ${ }^{2}$ is the key regulatory enzyme in CoASH biosynthesis (Scheme 1); kinetic analysis supports an ordered sequential mechanism, with ATP binding first $(11,12)$. CoASH is a competitive feedback inhibitor $\left(\mathrm{K}_{\mathrm{i}}=4.3 \mu \mathrm{M}\right)$ with respect to ATP (13), and crystal structures are available for the $E c$ PanK complexes with CoASH and with the non-hydrolyzable ATP analog AMPPNP, respectively (12), as well as for the ternary complex with ADP and Pan (14). There are now three types of bacterial PanK enzymes; the type I PanK found in E. coli is a P-loop kinase [kinase family and fold group 2 (15)], and Pan binding leads to a significant conformational change, resulting in closure of a "lid" over the bound substrate (14). EcPanK effectively phosphorylates the Pan antimetabolites (alternate substrates) $N$-pentyl- and $N$-heptylpantothenamide; $\mathrm{K}_{\mathrm{m}}$ values are only three-fold higher than that of the natural substrate (14). The phosphorylated products are carried through the CoASH biosynthetic pathway, resulting in the accumulation of inactive holo-acyl carrier proteins (16). Modeling studies indicate that the pantothenamides can orient into the Pan binding site, with their extended alkyl chains interacting with a hydrophobic "dome" over the substrate pocket.

In 2005, the bacterial type II and type III PanKs were identified in S. aureus (17), and in Helicobacter pylori and Bacillus subtilis (18), respectively. Neither isoform is similar in sequence to the type I EcPanK, nor is either subject to feedback inhibition by CoASH. Analysis of the respective kinetic parameters revealed a broad range for $\mathrm{K}_{\mathrm{m}}(\mathrm{ATP})$ values, from $34 \mu \mathrm{M}$ for $S a$ PanK to $3.1 \mathrm{mM}$ for $B s P a n K$. The type III $B s P a n K$ also exhibited a five-to-six-fold increase in $\mathrm{K}_{\mathrm{m}}(\mathrm{Pan})$ relative to $E c \mathrm{PanK}$ and $\mathrm{SaPanK}$; this correlates with the observation that N5-Pan is neither an alternate substrate for nor a competitive inhibitor of BsPanK. Limited bioinformatics analyses suggested that both type II and type III PanKs belonged to the ribonuclease H-like family [kinase family and fold group 4 (15)] of kinases (18). Very recently, Hong et al. (19) and Yang et al. (20) have confirmed these predictions with crystal structures for the type II SaPanK-AMPPNP complex and for the type III PanKs from Pseudomonas 
aeruginosa ( $\mathrm{PaPanK}$ ) and Thermotoga maritima (TmPanK), as well as the PaPanK-Pan complex.

Global sequence identities between $P a$ PanK and $T m P a n K$, respectively, and the type III PanK from the category A biodefense pathogen Bacillus anthracis are 25\% and 37\%.P.

aeruginos $a$ is a Gram-negative aerobe that also contains the GSH/GSSG/glutathione reductase thiol/disulfide redox system (21-23); T. maritima is an anaerobic rod-shaped

\author{
ABBREVIATIONS AND FOOTNOTES \\ CoADR \\ coenzyme A-disulfide reductase \\ CoaA \\ type I pantothenate kinase \\ PanK \\ pantothenate kinase \\ EcPanK \\ Escherichia coli pantothenate kinase \\ AMPPNP \\ 5'-adenylimido-diphosphate \\ Pan \\ pantothenate \\ N5-Pan \\ $N$-pentylpantothenamide \\ SaPanK \\ Staphylococcus aureus pantothenate kinase \\ BsPanK \\ Bacillus subtilis pantothenate kinase \\ PaPanK \\ Pseudomonas aeruginosa pantothenate kinase \\ TmPanK \\ Thermotoga maritima pantothenate kinase \\ $\mathrm{mBBr}$ \\ monobromobimane \\ NEM \\ $N$-ethylmaleimide \\ DTT \\ dithiothreitol \\ HPLC \\ high-performance liquid chromatography \\ BaPanK \\ Bacillus anthracis pantothenate kinase \\ SeMet \\ selenomethionine \\ MAD \\ multiwavelength anomalous dispersion \\ TIGR \\ The Institute for Genomic Research \\ ASKHA \\ Acetate and Sugar Kinase/Hsc70/Actin.
}


hyperthermophilic bacterium for which the ability to synthesize GSH has not been demonstrated (23). The CoADR enzymes, such as that from $S$. aureus $(7,24,25)$, are a key part of the intracellular machinery for those bacteria and archaea in which CoASH serves as the major low-molecular weight thiol. Our structure-based bioinformatics analysis (10) suggests that CoADR may be a more common activity than previously recognized and one that is significantly misannotated in databases. In this report we demonstrate that CoASH is the major low-molecular weight thiol in the Gram-positive facultative anaerobe B. anthracis. We also describe the crystal structure for the type III PanK from this spore-forming organism, as refined at $2.0 \AA$ Aresolution. The recent report of Yang et al. (20) included a bioinformatics analysis which demonstrates that the type III PanK is also widely distributed among bacteria. Here we provide an extended bioinformatics analysis that provides a genome-based link for the absence of GSH biosynthesis, the presence of the type III PanK, and the presence of CoADR-like enzymes in a number of bacteria (Gram-positive and Gram-negative) and spirochetes. Taken together, these observations suggest that the CoASH-refractory type III PanK plays a special role in maintaining higher intracellular CoASH levels in order to accommodate additional functions for the coenzyme in thiol/disulfide redox homeostasis in a diverse group of bacteria.

\section{EXPERIMENTAL PROCEDURES}

\section{Analysis of Thiols from $B$. anthracis}

A 1-L culture of B. anthracis Sterne was grown in Brain Heart Infusion medium (Becton, Dickinson, and Co.) and harvested in exponential-phase growth. Four pellets $(\sim 0.5 \mathrm{~mL}$ each) were extracted with $2.5 \mathrm{~mL}$ of $50 \%$ acetonitrile in $20 \mathrm{mM} N$-[2-hydroxyethyl]piperazine- $N^{\prime}$ [2-ethanesulfonic acid], $\mathrm{pH} 8$, containing $2 \mathrm{mM} \mathrm{mBBr}$ (Calbiochem), and incubated at $60^{\circ} \mathrm{C}$ for $15 \mathrm{~min}$ (26). The extract was cooled on ice and acidified with $5 \mu \mathrm{L}$ of $5 \mathrm{M}$ methanesulfonic acid. The pellet was removed by centrifugation and dried in a vacuum oven to constant weight. Four more pellets were extracted identically, except that $5 \mathrm{mMNEM}$ was substituted for $\mathrm{mBBr}$. A $0.5-\mathrm{mL}$ aliquot of one NEM-treated pellet was reacted with $2 \mathrm{mM} \mathrm{mBBr}$ for $15 \mathrm{~min}$ at $60^{\circ}$ $\mathrm{C}$ and acidified with methanesulfonic acid, as given above; this sample served as a control for the thiol samples. The remaining $\sim 2 \mathrm{~mL}$ of this sample was reacted with one eq of $\beta$ mercaptoethanol (based on NEM) and concentrated to $0.6 \mathrm{~mL}$ on a Speed Vac. This extract was reduced with $2 \mathrm{mM}$ DTT for $20 \mathrm{~min}$ at $23^{\circ} \mathrm{C}$ and then reacted with $\mathrm{mBBr}(8 \mathrm{mM}$ overall). The sample was acidified with methanesulfonic acid prior to HPLC analysis. A DTT sample was prepared as above, without extract, to serve as a control for the disulfide sample.

The extracts were analyzed following HPLC protocols 1 and 2 (26) for thiols and disulfides. Single point calibration standards were used for quantitation $(50 \mathrm{pmol})$ of the bimane derivatives of Cys, N-acetyl-Cys, GSH, thiosulfate $\left(\mathrm{SSO}_{3}{ }^{-2}\right), \mathrm{H}_{2} \mathrm{~S}$, mycothiol, $\mathrm{CoASH}, 3^{\prime}-$ dephospho-CoASH, pantetheine, and 4'-phosphopantetheine. The bimane derivative of CoASH hydrolyzes over time in acidic extracts to give the 3 -dephospho-CoASH-adduct and is quantitated as the sum of the two (CoASH + 3'-dephospho-CoASH) from HPLC protocol 2. The bimane derivatives of Cys, U12 (an unidentified B. anthracis thiol), pantetheine, 4'phosphopantetheine, and $\mathrm{H}_{2} \mathrm{~S}$ were best analyzed with protocol 1 .

\section{Expression and Purification of BaPanK and BA2901}

Genomic DNA from B. anthracis Ames was provided by Dr. Arthur Friedlander, U.S. Army Medical Research Institute of Infectious Diseases. B. anthracis PanK (NP_842634; "transcriptional activator, putative, Baf family") was expressed with a C-terminal His-tag provided by the pET28a plasmid vector in E. coli C41(DE3) cells. These cells were grown in a 3-L culture of tryptone-yeast extract-phosphate medium (27) supplemented with $30 \mathrm{mM}$ glucose and $30 \mu \mathrm{g} / \mathrm{mL}$ kanamycin at $37^{\circ} \mathrm{C}$. Cultures were induced with $0.5 \mathrm{mM}$ isopropyl- $\beta$ D-thiogalactopyranoside at an $\mathrm{A}_{600}$ of 0.9 and allowed to grow overnight at $37^{\circ} \mathrm{C}$. Following 
centrifugation at 5,000 $\times \mathrm{g}$ for $15 \mathrm{~min}$, the washed cell pellets were resuspended in $\sim 100 \mathrm{~mL}$ $25 \mathrm{mM}$ sodium phosphate, $\mathrm{pH} 7.0$, containing $2 \mathrm{mM}$ EDTA and $5 \mathrm{mM}$ DTT, and lysed via disruption with a pneumatic cell homogenizer (Avestin EmulsiFlex-C5). After centrifuging at $20,000 \times \mathrm{g}$, streptomycin sulfate was added ( $1 \% \mathrm{w} / \mathrm{v})$ to the supernatant, with stirring, for 15 $\mathrm{min}$. The supernatant obtained on subsequent centrifugation was filtered and loaded onto a QSepharose HP column equilibrated in $25 \mathrm{mM}$ sodium phosphate, $\mathrm{pH} 7.0$, with $5 \mathrm{mM} \beta$ mercaptoethanol. The protein was eluted with a $0 \rightarrow 1 \mathrm{M} \mathrm{NaCl}$ gradient in the loading buffer; fractions were analyzed by SDS-polyacrylamide gel electrophoresis. The $B a$ PanK pool was brought to final concentrations of $0.25 \mathrm{M} \mathrm{NaCl}$ and $20 \mathrm{mM}$ imidazole, and the $\mathrm{pH}$ was adjusted to 8.0 with $1 \mathrm{M} \mathrm{K}_{2} \mathrm{HPO}_{4}$. The protein was loaded onto a Ni-NTA Superflow (Qiagen) column equilibrated in $50 \mathrm{mM}$ sodium phosphate, $\mathrm{pH} 8.0$, containing $0.3 \mathrm{M} \mathrm{NaCl}$ and $5 \mathrm{mM} \beta$ mercaptoethanol. The His-tagged $B a$ PanK was eluted by increasing the imidazole concentration to $100 \mathrm{mM}$. The pure protein (calculated $m=29,915 \mathrm{Da}$ for the His-tagged $B a$ PanK) was buffer-exchanged into $25 \mathrm{mM}$ Tris- $\mathrm{HCl}, \mathrm{pH} 8.0$, containing $100 \mathrm{mM} \mathrm{KCl}, 0.5$ $\mathrm{mM}$ EDTA, and $0.5 \mathrm{mM}$ DTT and concentrated to $\sim 20 \mathrm{mg} / \mathrm{mL}$, based on a calculated $\varepsilon_{280}=$ $23,510 \mathrm{M}^{-1} \mathrm{~cm}^{-1}$ [ProtParam (28)]. After adding glycerol to $25 \%(\mathrm{v} / \mathrm{v}), 1-\mathrm{mL}$ aliquots were stored at $-80^{\circ} \mathrm{C}$. The SeMet derivative of $B a$ PanK was expressed from the pET28a-BaPanK vector in the $E$. coli $\mathrm{B} 834(\mathrm{DE} 3)$ strain (10); cultures were grown overnight in the auto-inducing medium PASM-5052 (29). The purification protocol for SeMet $B a$ PanK was essentially identical to that described for the native protein, except that the SeMet protein was eluted from the Ni-NTA column with $0.25 \mathrm{M}$ imidazole. Yields for the native and SeMet $B a$ PanKs were $\sim 200 \mathrm{mg}$ per L of culture and $\sim 30-35 \mathrm{mg}$ per L of culture, respectively.

The B. anthracis homolog (NP_845240; "hypothetical protein BA2901") of the type II SaPanK was expressed, with either $\mathrm{N}$-terminal or $\mathrm{C}$-terminal His-tags provided by the $\mathrm{pET} 28 \mathrm{a}$ plasmid vector, in $E$. coli B834(DE3) cells. These cells were grown in tryptone-yeast extract-phosphate medium, as described above for the $B a$ PanK expression and purification. N-terminal Histagged BA2901 was purified in the same way as $B a$ PanK, except that an SP-Sepharose HP column replaced the Q-Sepharose HP column in the first step, given the higher calculated pI of 8.7 for BA2901. For the C-terminal His-tagged protein, the pET28a clone was expressed in E. coli $\mathrm{B} 834(\mathrm{DE} 3)$ at $25^{\circ} \mathrm{C}$. The protein was purified with a combination of Q-Sepharose $\mathrm{HP}$ and Ni-NTA column steps and was stored at $-80^{\circ} \mathrm{C}$ in $50 \mathrm{mM}$ Tris- $\mathrm{HCl}, \mathrm{pH} 7.4$ (at $25^{\circ} \mathrm{C}$ ), containing $1 \mathrm{mM}$ DTT and $20 \%$ glycerol (v/v).

\section{PanK Assays}

The enzymatic activity of purified $B a \mathrm{PanK}$ was measured as recently described for $\mathrm{PaPanK}$ (19); the standard assay included $60 \mathrm{mM} \mathrm{NH}_{4} \mathrm{Cl}$ to allow for activation of the enzyme in the presence of the monovalent cation. The purified BA2901 protein was assayed following the protocol described for $\mathrm{SaPanK}$ (17). We also tested the ability of BA2901 to complement the E. coli mutant strain DV70 [coaA(Ts)] (30) that is unable to grow at $42^{\circ} \mathrm{C}$ due to the inactivation of $E c$ PanK. Control strains were obtained by transforming strain DV70 with either pSC4, a pET28a plasmid harboring the $S$. aureus coaA gene (17), or with the empty vector. All strains grew very well at $30^{\circ} \mathrm{C}$, but only pSC4/DV70 grew $(36 \mathrm{~h})$ at $42^{\circ} \mathrm{C}$.

\section{Crystallization and Data Collection}

Thawed aliquots of the native and SeMet $B a$ PanK proteins were buffer-exchanged into $10 \mathrm{mM}$ sodium $N$-[2-hydroxyethyl]piperazine- $N$ '-[2-ethanesulfonic acid] to give final protein concentrations of $22-24 \mathrm{mg} / \mathrm{mL}$. The native protein as concentrated $(\mathrm{pH} 7.0)$ also included 50 $\mathrm{mM} \mathrm{KCl}$; the SeMet protein sample (pH 7.5) contained $10 \mathrm{mM} \mathrm{KCl}$. Crystals were grown in 24-well sitting-drop plates over reservoirs of $0.5 \mathrm{~mL} 24-26 \%$ ethylene glycol, in drop sizes of either $2+2$ or $4+4 \mu \mathrm{L}$. Crystals were flash-frozen in a nitrogen stream at $100 \mathrm{~K}$ directly after 
being removed from the drop. Data sets for MAD phasing were collected at National Synchrotron Light Source beamline X12C.

\section{Phasing and Structure Refinement}

Images in each data set were indexed, integrated, and scaled in $\mathrm{d}^{*}$ TREK (31). Phasing, chain tracing, and density modification were performed with SOLVE/RESOLVE (32-34). Model refinement was carried out in CNS (35), with manual rebuilding in COOT (36). The latter stages of refinement were performed with REFMAC5 (37). The final model was validated with MOLPROBITY (38) and with the built-in tools from COOT.

\section{Bioinformatics}

Sequence analyses with $B a$ PanK were performed with the NCBI (39) and SEED (40) databases using blastp. Multiple sequence alignments were performed with CLUSTALW (41).

Secondary structural motifs were identified with DSSP (42), and structural homology searches were performed with the Combinatorial Extension [CE (43)] and DALI (44) web servers. Structural alignments and analyses were carried out in COOT, and structure-based sequence alignments were exported with SSM SUPERPOSE (45). The TIGR-Comprehensive Microbial Resource (46) Version 2.3 (Genomes Region Comparison tool; Data Releases through 19.0) and the Integrated Microbial Genomes Version 1.6 (phylogenetic distribution tool) were used to identify proteins similar to those in the test set, in other bacteria. The test set included $E$. coli GshA (NP_417173), E. coli GshB (NP_417422), Streptococcus agalactiae $\gamma$ glutamylcysteine synthetase-glutathione synthetase (NP_688811), E. coli type I PanK (NP_418405), S. aureus type II PanK (NP_646871), B. subtilis type III PanK (AAW83041), and S. aureus CoADR (YP_493573). Strong evidence for homology is provided by a sequence identity of $\geq 25 \%$ (47); alignments for determining pairwise identities were performed using LALIGN [default parameters (48)].

\section{RESULTS AND DISCUSSIONS}

\section{CoASH in Bacillus anthracis}

In order to analyze thiols from B. anthracis, samples were taken from a 1-L culture of $B$. anthracis Sterne harvested in exponential-phase growth; bimane derivatives of low-molecular weight thiols resolved by reverse phase HPLC are given in Figure 1. B. anthracis produces CoASH, cysteine, and $\mathrm{H}_{2} \mathrm{~S}$; the $\mathrm{H}_{2} \mathrm{~S}$ is likely derived from iron-sulfur proteins and is not a low-molecular weight thiol. This profile is qualitatively similar to that reported for $\boldsymbol{B}$. subtilis, but differs quantitatively in the relative amounts of CoASH and cysteine. GSH, pantetheine, and 4'-phosphopantetheine were not detectable $[\leq 0.03 \mu \mathrm{mol} / \mathrm{g}$ (dry residual weight)]. Total CoASH was estimated at $0.87 \pm 0.11 \mu \mathrm{mol} / \mathrm{g}$ (dry residual weight), very similar to the value of $1.1 \pm 0.1 \mu \mathrm{mol} / \mathrm{g}$ (dry residual weight) reported for $S$. aureus (7). A new unknown thiol (U12) was also identified in the B. anthracis extract; purification and mass spectrometric analysis gave a mass of $397 \mathrm{Da}$ for $\mathrm{U} 12^{3}$ (corrected for the bimane contribution); this thiol could not be identified by comparison with the retention times for known thiols as analyzed in HPLC protocols 1 and 2 (see "Experimental Procedures"). Parallel analyses for the corresponding low-molecular weight disulfides [CoA-disulfide $\leq 0.035 \mu \mathrm{mol} / \mathrm{g}$ (dry residual weight)] gave an intracellular ratio of $\mathrm{CoASH} / \mathrm{CoA}$-disulfide $>50$. The method used to determine disulfides involves treatment of thiol-blocked extracts with DTT, in order to reduce the disulfide to its thiol form for $\mathrm{mBBr}$ derivatization and analysis. Since DTT can also release CoASH from acyl-CoAs by transacetylation (49), the value determined in this way represents

\footnotetext{
${ }^{3}$ A mixed disulfide form of the oxidized OhrR repressor has very recently been identified that is formed in $B$. subtilis cells on treatment with cumene hydroperoxide; the novel thiol component also gives a mass of $397 \mathrm{Da}$ (J. Helmann, personal communication).
} 
an upper limit for the disulfide content; the estimated CoASH/CoA-disulfide ratio therefore represents a lower limit. Using a value of $2 \mu \mathrm{L} / \mathrm{mg}$ dry weight for the cell volume, we estimate the concentration of CoASH in B. anthracis cells to be $\sim 0.44 \mathrm{mM}$. The concentration of CoASH in $E$. coli $(1.5 \mu \mathrm{L} / \mathrm{mg}$ dry weight) can similarly be estimated at $\sim 0.4 \mathrm{mM}$ (22).

\section{PanKs in B. anthracis}

The conversion of Pan $\rightarrow \mathrm{CoASH}$ requires three gene products, in addition to the type I PanK, in E. coli (Scheme 1): the bifunctional phosphopantothenoylcysteine synthetase/decarboxylase (phosphopantothenate + cysteine $\rightarrow \longrightarrow 4^{\prime}$-phosphopantetheine; coaBC), phosphopantetheine adenylyltransferase (coaD), and dephospho-CoASH kinase (coaE). With specific reference to CoASH biosynthesis in B. anthracis, Gerdes et al. (50) published an analysis of potential broadspectrum antimicrobial drug targets among cofactor biosynthetic pathways; all four coa gene products in E. coli were concluded to be individually "essential," as was the acpS gene product which synthesizes the holo-acyl carrier protein from CoASH + apo-acyl carrier protein (51). Using the ERGO database and the B. anthracis Ames genome sequence, the predicted CoASH biosynthetic pathway for the anthrax pathogen was analyzed with the aid of the known $E$. coli pathway (50). All components of the de novo Pan biosynthetic pathway, as well as the $\mathrm{Na}^{+} /$Pan transporter, were identified (presence of the orthologous gene); similar results were found for the pathway from Pan $\rightarrow \mathrm{CoASH}$, except for the type I PanK. The locus identified in this case was the ortholog of the eukaryotic panK gene ["hypothetical protein BA2901" (NP_845240)], and the properties of the BA2901 protein are described below. Choudhry et al. (52) later demonstrated that the type II $S$. aureus PanK was closely related to BA2901 as well (35\% identity), and both Choudhry et al. (52) and Genschel et al. (53) have suggested that this $B$. anthracis protein, which is also related to the human PanK, has likely arisen as the result of lateral gene transfer. We expressed and purified recombinant BA2901 with $\mathrm{N}$ - and C-terminal His-tags, respectively; the mass of the former $(33.6 \mathrm{kDa})$ was verified by matrix-assisted laser desorption/ionization time-of-flight mass spectrometry (Bruker Autoflex; sinapinic acid matrix). Both purified proteins were inactive in the in vitro PanK assay, under conditions in which the purified $\mathrm{SaPanK}$ is fully active. In addition, the BA2901 pET28a expression plasmid failed to complement the E. coli coaA(Ts) strain DV70 under conditions where $S$. aureus coaA-pET28a restored growth at $42^{\circ} \mathrm{C}$. A homology model for BA2901 based on the type II $S a$ PanK structure (19) does not provide an explanation for the observed lack of activity. No crystal structure for the $\mathrm{SaPanK}$-Pan complex is available; the model described by Hong et al. (19) represents a "loose fit" for bound Pan. The critical residues involved in Pan binding have not been strictly identified or tested. Similarly, a putative mammalian PanK (PanK4) was originally identified based on its very favorable comparison with the mammalian PanK1 sequence, but this protein is also inactive. We conclude that BA2901 is very likely a kinase of the ribonuclease H-like family, but Pan is not the acceptor substrate. Genetic studies already in progress ${ }^{4}$ are designed to provide a more definitive answer to this question. If BA2901 does lack compensating PanK activity, deletion of the BA0065 locus should be lethal to $B$. anthracis Sterne (see below).

The absence of a type I PanK (and perhaps a functional type II enzyme as well, see above) in B. anthracis is distinct from the situation in B. subtilis and Bacillus halodurans, where functional type I and III enzymes are found $(18,54)$. In B. subtilis, deletion of the coaX (type III) gene gave a normal growing phenotype, but $\operatorname{coa} X$ could not be deleted from a strain containing a coaA deletion; these results suggested that simultaneous deletion of both genes was lethal to B. subtilis. The B. anthracis Ames genome (55) also yields a type III PanK homolog, annotated as "putative Baf family transcriptional activator BA0065" (NP_842634), which is $76 \%$ identical to the functional $B s P a n K$. Of those bacterial species referred to earlier,

${ }^{4}$ C. Paige, P. Hanna, and A. Claiborne, unpublished experiments. 
known to lack GSH and containing CoASH as their major low-molecular weight thiol, $B$. burgdorferi, D. radiodurans, and B. megaterium5 all have type III PanK homologs (20); all lack both type I and II PanK genes. All members of the Bacillus cereus group lack coaA orthologs, and all completed genomes of this group (B. anthracis, B. cereus, and Bacillus thuringiensis) contain type III PanK homologs 95-100\% identical to that of the $B$. anthracis Ames strain. The bacterial type II and III PanK enzymes examined thus far are refractory to inhibition by CoASH (17-19), suggesting that bacteria dependent on CoASH as the major intracellular thiol tend to possess CoASH biosynthetic pathways insensitive to feedback inhibition.

The C-terminal His-tagged BA0065 protein $(\mathrm{BaPanK})$ was expressed and purified from recombinant $E$. coli; in contrast to the BA2901 protein, $B a \mathrm{PanK}$ is active in the in vitro enzyme assay, as examined in parallel with the type III $P a$ PanK. $B a$ PanK gives $60 \%$ conversion of D $\left[1-{ }^{14} \mathrm{C}\right]$ pantothenate to $4^{\prime}$-phosphopantothenate under conditions where $\mathrm{PaPanK}$ gives $40 \%$ conversion.

\section{Structure Solution of BaPanK}

The structure of $B$. anthracis PanK was solved by three-wavelength MAD phasing with the SeMet-substituted protein. Statistics for the data sets and final structure model are shown in Tables 1 and 2, respectively. Ten Se sites were identified, and the experimental MAD-phased electron density map calculated at $2.0 \AA$ showed continuous electron density for the protein backbone, with the exception of a stretch of seven residues (Arg164-Arg170), and allowed identification of most side chain positions. The $2 F_{o}-F_{c}$ map in the region of the PHOSPHATE1 motif (see below) also illustrates the accuracy of the final refined model (Figure 2). The Cterminus, including residues Asn255-Glu262 plus the $\mathrm{His}_{6}$ tag, is not visible in the electron density map; the model is truncated at Ala254. The crystal structure of $B a \mathrm{PanK}$ has one monomer in the asymmetric unit. Residues 164-170 are part of a long loop spanning residues Ser163-Asn183; the length of this loop, its location on the surface of the protein, and the absence of electron density for a part of it suggest that the entire loop is flexible. Yang et al. (20) have described the equivalent loop in TmPanK as comprising the "Pan cap."

The two constituent monomers of the $B a$ PanK dimer are related by crystallographic symmetry (a two-fold rotation axis). Each monomer interacts with the other through a region consisting of $\beta 3^{\prime}, \alpha a, \alpha 1^{\prime}$, and the C-terminal part of the loop between $\beta a$ and $3_{10} b$ (Figure 3). As expected, structural superpositions with the $B a$ PanK monomer and either $P a$ PanK (19) or $T m$ PanK (20) reveal nearly identical folds for the three type III PanKs; $\mathrm{C}_{\alpha}$ rmsd values of 2.1 and $1.6 \AA$ result with the respective A monomers (for 217 and 232 atoms, respectively). The type III PanKs have been identified as members of the ASKHA kinase superfamily [ribonuclease $\mathrm{H}-$ like, group 4 (15)]. Figure 4 gives a structure-based sequence alignment for the five known functional type III PanKs. As described, all share the three major sequence-structure motifs (56) attributed to the ASKHA superfamily (PHOSPHATE1, PHOSPHATE2, and ADENOSINE), as well as the interdomain helix-to-helix CONNECT elements (Ala116 and Gly245 in $B a$ PanK). The three major ASKHA motifs correspond to elements involved in ATP recognition and binding as well as divalent metal coordination for the relevant phosphotransferase (PanK) activity $(15,56)$.

\section{PAN and INTERFACE Motifs}

$B a$ PanK has few insertions to its core ASKHA fold. Other members of the ASKHA superfamily, including the type II SaPanK (17) and the eukaryotic PanKs (15), have several such insertions which adopt structures and motifs responsible for the formation of unique substrate-binding sites. Based on the structure for the PaPanK-Pan complex [2F9W (19)], a model of the BaPanK-Pan complex was developed. Most of the interactions between protein 
and Pan occur with residues that are outside the ASKHA motifs; two insertions to the core fold in $B a$ PanK merit special attention. Broadly speaking, Pan binds in a pocket formed between $\beta 3^{\prime}$ and the loop connecting $3_{10} \mathrm{~b}$ and $\alpha 3^{\prime}$ (Figure 5); this loop bears the conserved residues Gly107, Asp109, and Arg 110 [the $h$ G $h$ DR sequence; $h=$ hydrophobic (Figure 4)] and constitutes the new PAN motif. Strand $\beta 3^{\prime}$ bears the conserved residues Gly147, Gly148, and Ile150, which play roles in Pan binding, as well as Pro152 and Gly153, which are important in the context of the dimer interface; together, these residues constitute the new INTERFACE motif [the GG $x$ I $x$ PG sequence (Figure 4)]. These new PAN and INTERFACE motifs are found in all type III PanK proteins (Figure S1) and serve to distinguish this from other ASKHA families; an inspection of the eukaryotic PanK family alignment (15) reveals that the PAN and INTERFACE motifs are unique to the type III sequences.

BaPanK Asp109 forms side chain hydrogen bonds to the Pan C2'- and C4'-hydroxyls (Figure 6); this Asp is conserved within the PAN motif in the type III PanK sequences. BaPanK Gly 107$\mathrm{N}$ [this Gly is also conserved within the PAN motif (Figure 4)] forms a hydrogen bond with the Pan C1-carboxylate. In addition, the absence of a side chain here avoids a potential steric clash with the bound substrate. $B a$ PanK Arg 110 of the PAN motif (conserved in all known functional type III PanKs) and Tyr100 also interact with the Pan carboxylate. The Asp109 and Arg 110 side chain rotamers, which form hydrogen bonds with Asp6 and Thr135, respectively, in the apoenzyme, are adjusted in the BaPanK-Pan model to optimize the interactions with bound Pan. Inspection of the TmPanK structure (20) and the TmPanK-Pan model reveals that a change in the apoenzyme Arg 106 rotamer would also be necessary for optimization of that Pan-binding interaction.

Within the INTERFACE motif, Gly147 and Gly148 provide space at the end of the binding pocket for the Pan carboxylate. Any side chain at either of these positions would produce steric clashes with the bound Pan. Ile150 makes van der Waals contacts with bound Pan, while Pro152 and Gly153 are conserved, not for Pan binding, but for their roles in dimerization as described earlier. Conserved regions in the type II SaPanK (17) and the eukaryotic PanKs (15) do not correlate with either the PAN or INTERFACE motifs; Hong et al. (19) have demonstrated that, although the $\mathrm{SaPanK}$ and $\mathrm{PaPanK}$ monomers have similar structures (SSM SUPERPOSE gives $\mathrm{a} \mathrm{C}_{\alpha} \mathrm{rmsd}=2.9-3.1 \AA$ for 195 atoms), the respective homodimers assemble with distinctly different architectures. The $\mathrm{SaPanK}$-Pan model suggests that Glu70, which is structurally equivalent to $\mathrm{PaPanK}$ Asp101, interacts with the Pan C4'-OH; this Glu residue does not, however, appear within any PAN-like motif. SaPanK Arg113, implicated in contact with the Pan C1-carboxylate, follows by 43 residues in the sequence (in contrast to the $h \mathrm{G} h \mathrm{DR}$ motif in the type III PanKs). Further inspection of the $\mathrm{SaPanK}$ sequence reveals that Arg113 is followed closely by Gly115-Gly116; these Gly residues are structurally equivalent to the conserved Gly147-Gly148 pair described for the INTERFACE motif of the type III PanKs.

In the context of the dimer, the importance of another region in the type III PanKs becomes apparent; this region represents a unique insertion element, as compared with the type II $\mathrm{SaPanK}$. The segment corresponding to BaPanK Leu161-Val180 (TmPanK 159-178 and $\mathrm{Pa}$ PanK 153-176) is observed to exhibit different conformations in the three structures (Figure 7). Helix $\alpha \mathrm{a}$ is present in all three structures to some degree, but the subsequent loop leading to helix a1' shows significant differences. Similarly, residues 164-170 lack electron density in the $B a$ PanK structure. Yang et al. (20) describe several residues in this region as part of the "Pan cap" which contributes to the conserved hydrophobic pocket described earlier (including elements of the INTERFACE motif) that accommodates the two C3'-methyl groups of bound Pan. This cap is also proposed to protect the Pan-binding site - and the bound Pan substrate from solvent. 
The differential ordering/disordering of this region in the three distinct type III PanK structures cannot be explained in the context of the respective crystal lattices. Furthermore, the ordering of the region in monomer $\mathrm{B}$ of the apo-PaPanK structure (versus its disordering in monomer A) is nearly identical to that seen in both monomers of the $P a$ PanK-Pan structure, so the conformational differences cannot be explained by the simple absence or presence of bound substrate. These observations have led to a preliminary examination of the conformational dynamics for the Pan cap. Our structural model for the $B a$ PanK-Pan complex is stable under energy minimization. ${ }^{6}$ In the same short molecular dynamics simulations, the Pan substrate diffuses out of its binding site in the $B a$ PanK dimer, suggesting that the unresolved loop nearby plays a role in binding the substrate. In addition to local rearrangements expected in the active site on Pan binding, domain closure may play a role in strengthening the interactions within the enzyme-substrate complex, as well as in excluding solvent from the phosphotransferase reaction center.

A conserved Thr residue near this flexible region shows a specific interaction with the bound Pan. In the model of the $B a$ PanK-Pan complex, though a large part of the long loop is missing electron density, Thr184' is in nearly the same relative position as PaPanK Thr180' (Figure 6), suggesting that this residue is conserved in order to stabilize Pan in its binding site. Thr180' of $\mathrm{PaPanK}$ monomer B forms a hydrogen bond with the Pan carboxylate bound to monomer A.

\section{Interactions with CoASH}

CoASH is an important feedback inhibitor of the type I PanK, exhibiting a $\mathrm{K}_{\mathrm{i}}$ of $4.3 \mu \mathrm{M}$ (13); binding is competitive with respect to ATP, and crystal structures of the EcPanK-AMPPNP and -CoASH complexes (12) demonstrated that the $\alpha$ - and $\beta$-phosphates of CoASH occupy the same site as the $\beta$ - and $\gamma$-phosphates of ATP. In both cases, Lys 101 is essential in mediating the interactions with the phosphate moieties (11). His 177, Phe247, and Arg 106 are unique and essential to CoASH binding and inhibition; H177Q, F247V, and R106A EcPanK mutants are all refractory to any inhibition at $[\mathrm{CoASH}] \leq 160 \mu \mathrm{M}$, nor do the mutants bind $\mathrm{CoASH}$ in equilibrium dialysis experiments (57). In the crystal structure of the $E c$ PanK-CoASH complex, the CoASH $\beta$-mercaptoethylamido moiety extends into the hydrophobic dome over the Panbinding pocket; the same hydrophobic residues that interact with the extended alkyl chain of N5-Pan also form the binding groove for the $\beta$-mercaptoethylamido moiety of CoASH (12). The thiol group is tightly sealed from solvent by weakly polar interactions with four aromatic residues from the hydrophobic dome and also participates in a hydrogen bond with the CoASH adenine 6- $\mathrm{NH}_{2}$ group.

Although many of the protein elements defined in the EcPanK-CoASH interaction are absent in $B a$ PanK, the most direct explanation for the failure of the type III PanKs to exhibit feedback inhibition by CoASH lies in the tight Pan-binding pocket seen in the BaPanK-Pan model (Figure 7). The absence of the hydrophobic dome results in an inability to accommodate the $\beta$-mercaptoethylamido moiety of CoASH, in parallel with the failure to accommodate the alkyl substituents of N5-Pan and $N$-heptylpantothenamide. An identical conclusion regarding the absence of CoASH inhibition with the type III TmPanK has recently been given by Yang et al. (20). As the type II $\mathrm{SaPanK}$ Pan-binding pocket is fully exposed and can bind the pantothenamides (19), other factors must explain the resistance of $\mathrm{SaPanK}$ to CoASH feedback inhibition. The biological consequences of these analyses are considered in the following section.

${ }^{6}$ F.R. Salsbury, N.I. Nicely, and A. Claiborne, unpublished experiments. 


\section{Type III PanKs and CoASH-Dependent Redox Biology}

In the specific case of $S$. aureus, GSH is absent, as described earlier (7). CoASH is the major intracellular thiol, and a unique NADPH-dependent CoADR functions to maintain the appropriate intracellular thiol/disulfide redox balance, analogous to the GSH/GSSG/ glutathione reductase system in E. coli $(10,24,25)$; in $S$. aureus, the ratio of CoASH/CoAdisulfide is about 450 . The presence of the type II PanK in $S$. aureus $(17,19)$, which is refractory to inhibition by CoASH, allows CoASH levels to rise to an upper limit (calculated to be $\sim 0.55$ $\mathrm{mM}$ ) likely controlled only by the supply of Pan, thus contributing to this organism's unique CoASH-dependent redox biology. Bacterial type II PanK homologs have been identified only in Staphylococcus, in the B. cereus group, and in Oceanobacillus iheyensis (20). In this work, however, we have been unable to demonstrate the catalytic ATP-dependent phosphorylation of Pan in vitro, using two different His-tagged versions of the purified recombinant type II PanK homolog from B. anthracis (BA2901); nor does the BA2901 expression plasmid complement the temperature-sensitive E. coli coaA mutant strain DV70. Our working conclusion for $B$. anthracis is that the type III PanK may represent the sole functional enzyme for synthesis of 4 '-phosphopantothenate; genetic studies already in progress 4 are designed to provide a conclusive answer to this question. The bioinformatics analysis of Copley and Dhillon (23), combined with biochemical analyses reported by the Fahey laboratory over the past 30 years (1), demonstrate that GSH biosynthesis is found "only rarely" in Gram-positive bacteria. The demonstration that functional CoADR enzymes are present in $S$. aureus (7), in B. megaterium (4) and B. anthracis 7, and in B. burgdorferi (8) correlates perfectly with the presence of CoASH as the major low-molecular weight thiol, and with the presence of a type II or type III PanK.

In B. megaterium spores (58), $43 \%$ of the total CoASH was shown to be present as soluble protein-SSCoA disulfides; $>75 \%$ of this protein-SSCoA disulfide pool was reduced within the first minutes of germination. Two likely functions for these protein-SSCoA disulfides were considered: 1) reversible inactivation of key thiol-dependent spore enzymes, maintaining metabolic dormancy in the spore, and 2) reversible protection of labile protein thiols in the spore, thereby contributing to heat and radiation resistance. The protein-SSCoA disulfide pool in vegetative $B$. megaterium accounted for $<2 \%$ of the total CoASH but increased dramatically to $\sim 45 \%$ of the total CoASH during sporulation. Formation and reduction of these proteinSSCoA disulfides (during spore formation and germination, respectively) has been attributed to a CoASH-mediated redox control process. The effective absence of reduced pyridine nucleotides (NADH and NADPH) in dormant spores of $B$. megaterium (59) corresponds to a dramatic decrease in the intracellular [CoASH]/[CoA-disulfide] redox state, which corresponds in turn to maximal protein-SSCoA disulfide formation. The rapid accumulation of NADH during the first minutes of spore germination (59) has been proposed to lead to reduction of the protein-SSCoA disulfide pool, either directly by a CoADR-like enzyme or indirectly, via a CoASH-mediated process (4).

The potential importance of such a CoASH-mediated germination control mechanism in $B$. anthracis is clear, as spore germination and outgrowth are fundamental to proliferation (60). The analysis of the transcriptome activated during growth and sporulation of B. anthracis Sterne has provided additional support for this hypothesis (61). The $\operatorname{coa} X$ gene encoding $B a$ PanK is up-regulated in wave II, as is the coaD locus encoding phosphopantetheine adenylyltransferase; the $\operatorname{coaBC}$ and $\operatorname{coaE}$ genes corresponding to the bifunctional phosphopantothenoylcysteine synthetase/decarboxylase and dephospho-CoASH kinase, respectively, are up-regulated in waves I and III. Bergman et al. (61) have suggested, that since waves I and II are the phases of the B. anthracis life cycle that occur within the infected host, genes up-regulated specifically within this temporal frame may be particularly useful as therapeutic targets. The B. anthracis CoADR (BA1263) and CoADR-rhodanese homology 
domain (BA0774) proteins were expressed in waves III and V, respectively, and the presence of CoADR in the fractured spore was confirmed by proteomics analysis (62). At least four gene products essential for biosynthesis of the CoASH precursors Pan (BA1562, BA1563, and BA1564) and cysteine (BA1831) were also expressed in wave V. As described by Bergman et al. (61), waves IV and V seem to represent the final stages of sporulation in B. anthracis and include a large number of sporulation-associated loci as well as loci involved in oxidative stress responses.

In collaboration with Dr. Jacques Ravel of TIGR, we have undertaken a bioinformatics analysis using 1) the E. coli gsh $A$ and $g s h B$ genes (23), along with the bifunctional $\gamma$-glutamylcysteine synthetase-glutathione synthetase (SAG1821) gene from Streptococcus agalactiae (63), 2) the $S$. aureus CoADR gene (24), and 3) the E. coli type I (64), S. aureus type II (17), and B.

subtilis type III (18) PanK genes, together with the TIGR Comprehensive Microbial Resource (version 2.3; Data Releases through 19.0). Table 3 lists those bacteria (genomes available as of April, 2006) which lack the ability to synthesize GSH, contain a type II or type III PanK, and contain a CoADR-like protein. Of the 27 species represented, for which we conclude that a CoASH-dependent redox biology pertains, only the four staphylococcal species lack the type III PanK. The absence of GSH has been confirmed for seven of the 27 species, and CoASH is known to be the major low-molecular weight thiol in six of these. It is of interest to note that even though mycothiol is the major low-molecular weight thiol in Streptomyces coelicolor and other streptomycetes (22), the level of intracellular CoASH is similar to that in S. aureus. CoADR-like proteins (E values $\left.=4 \mathrm{e}^{-41}-6 \mathrm{e}^{-39}\right)$ are present in both $S$. coelicolor and Streptomyces avermitilis, suggesting a redundancy in low-molecular weight thiol/disulfide redox systems for this organism. As CoASH has been identified as an important component of the sporulation process in B. megaterium (see above), the CoASH/CoA-disulfide/CoADR system may also function in spore formation for streptomycetes.

In a parallel analysis, using the Integrated Microbial Genomes resource (65), 14 phylogenetic classes of bacteria (among the 30 classes analyzed) were identified as lacking the three marker proteins for GSH biosynthesis (GshA, GshB, and $\gamma$-glutamylcysteine synthetase-glutathione synthetase), and we conclude that these organisms lack the ability to synthesize GSH. All 14 classes also lack the type I PanK, and 13 of these classes have the CoASH-refractory type III PanK; eight classes have both the type III PanK plus a CoADR-like protein. It should, of course, be emphasized that other important bacteria such as Pseudomonas aeruginosa have been demonstrated to contain millimolar levels of GSH (22); still they express only the type III PanK $(19,20)$. Analysis of the Helicobacter pylori genome has been reported to reveal the absence of $g s h A$, gor, and $g r x$ genes (66), implying the lack of a GSH/GSSG/glutathione reductase thiol/disulfide redox system. Thus, of the five known functional type III PanKs, only one is derived from a GSH-dependent microorganism ( $P$. aeruginosa).

\section{Supplementary Material}

Refer to Web version on PubMed Central for supplementary material.

\section{ACKNOWLEDGMENT}

We would like to thank Dr. Arthur Friedlander for kindly providing B. anthracis genomic DNA, Dr. Fred Salsbury for performing the molecular dynamics calculations, Dr. Don Guiney for providing B. anthracis Sterne cultures, Dr. Hee-won Park for providing coordinates prior to publication, Mr. William Boles for support during data collection at the National Synchrotron Light Source, and Ms. Sumana Choudhury for excellent technical assistance in expressing the $B a$ PanK and BA2901 proteins. We also thank Dr. Jacques Ravel for hosting one of us (C.P.) in his laboratory and contributing to the bioinformatics analysis. 


\section{REFERENCES}

1. Fahey RC. Novel thiols of prokaryotes. Annu. Rev. Microbiol 2001;55:333-56. [PubMed: 11544359]

2. Ortenberg R, Beckwith J. Functions of thiol-disulfide oxidoreductases in E. coli: redox myths, realities, and practicalities. Antioxid. Redox Signal 2003;5:403-11. [PubMed: 13678528]

3. Fahey, RC.; Newton, GL. Occurrence of low molecular weight thiols in biological systems. In: Larsson, A., et al., editors. Functions of Glutathione: Biochemical, Physiological, Toxicological, and Clinical Aspects. Raven Press; New York: 1983. p. 251-260.

4. Swerdlow RD, Setlow P. Purification and characterization of a Bacillus megaterium disulfide reductase specific for disulfides containing pantethine 4',4"-diphosphate. J. Bacteriol 1983;153:475-84. [PubMed: 6401287]

5. Newton, GL.; Fahey, RC. Glutathione in prokaryotes. In: Vina, J., editor. Glutathione: Metabolism and Physiological Functions. CRC Press; Boca Raton, FL: 1990. p. 69-77.

6. Hummel CS, Lancaster KM, Crane EJ 3rd. Determination of coenzyme A levels in Pyrococcus furiosus and other Archaea: implications for a general role for coenzyme A in thermophiles. FEMS Microbiol. Lett 2005;252:229-234. [PubMed: 16213671]

7. delCardayre SB, Stock KP, Newton GL, Fahey RC, Davies JE. Coenzyme A disulfide reductase, the primary low molecular weight disulfide reductase from Staphylococcus aureus. Purification and characterization of the native enzyme. J. Biol. Chem 1998;273:5744-51. [PubMed: 9488707]

8. Boylan JA, Hummel CS, Benoit S, Garcia-Lara J, Treglown-Downey J, Crane EJ 3rd, Gherardini FC. Borrelia burgdorferi bb0728 encodes a coenzyme A disulfide reductase whose function suggests a role in intracellular redox and the oxidative stress response. Mol. Microbiol 2006;59:475-486. [PubMed: 16390443]

9. Harris DR, Ward DE, Feasel JM, Lancaster KM, Murphy RD, Mallett TC, Crane EJ 3rd. Discovery and characterization of a Coenzyme A disulfide reductase from Pyrococcus horikoshii. Implications for the disulfide metabolism of anaerobic hyperthermophiles. FEBS J 2005;272:1189-200. [PubMed: 15720393]

10. Mallett TC, Wallen JR, Karplus PA, Sakai H, Tsukihara T, Claiborne A. Structure of Coenzyme ADisulfide Reductase from Staphylococcus aureus at 1.54 A Resolution. Biochemistry 2006;45:11278-11289. [PubMed: 16981688]

11. Song WJ, Jackowski S. Kinetics and regulation of pantothenate kinase from Escherichia coli. J. Biol. Chem 1994;269:27051-8. [PubMed: 7929447]

12. Yun M, Park CG, Kim JY, Rock CO, Jackowski S, Park HW. Structural basis for the feedback regulation of Escherichia coli pantothenate kinase by coenzyme A. J. Biol. Chem 2000;275:280939. [PubMed: 10862768]

13. Vallari DS, Jackowski S, Rock CO. Regulation of pantothenate kinase by coenzyme A and its thioesters. J. Biol. Chem 1987;262:2468-71. [PubMed: 3029083]

14. Ivey RA, Zhang YM, Virga KG, Hevener K, Lee RE, Rock CO, Jackowski S, Park HW. The structure of the pantothenate kinase-ADP.pantothenate ternary complex reveals the relationship between the binding sites for substrate, allosteric regulator, and antimetabolites. J. Biol. Chem 2004;279:356229. [PubMed: 15136582]

15. Cheek S, Ginalski K, Zhang H, Grishin NV. A comprehensive update of the sequence and structure classification of kinases. BMC Struct. Biol 2005;5:6. [PubMed: 15771780]

16. Zhang YM, Frank MW, Virga KG, Lee RE, Rock CO, Jackowski S. Acyl carrier protein is a cellular target for the antibacterial action of the pantothenamide class of pantothenate antimetabolites. J. Biol. Chem 2004;279:50969-75. [PubMed: 15459190]

17. Leonardi R, Chohnan S, Zhang YM, Virga KG, Lee RE, Rock CO, Jackowski S. A pantothenate kinase from Staphylococcus aureus refractory to feedback regulation by coenzyme A. J. Biol. Chem 2005;280:3314-22. [PubMed: 15548531]

18. Brand LA, Strauss E. Characterization of a new pantothenate kinase isoform from Helicobacter pylori. J. Biol. Chem 2005;280:20185-8. [PubMed: 15795230]

19. Hong BS, Yun MK, Zhang YM, Chohnan S, Rock CO, White SW, Jackowski S, Park HW, Leonardi R. Prokaryotic type II and type III pantothenate kinases: The same monomer fold creates dimers with distinct catalytic properties. Structure 2006;14:1251-61. [PubMed: 16905099] 
20. Yang K, Eyobo Y, Brand LA, Martynowski D, Tomchick D, Strauss E, Zhang H. Crystal structure of a type III pantothenate kinase: insight into the mechanism of an essential coenzyme A biosynthetic enzyme universally distributed in bacteria. J. Bacteriol 2006;188:5532-40. [PubMed: 16855243]

21. Perry AC, Ni Bhriain N, Brown NL, Rouch DA. Molecular characterization of the gor gene encoding glutathione reductase from Pseudomonas aeruginosa: determinants of substrate specificity among pyridine nucleotide-disulphide oxidoreductases. Mol. Microbiol 1991;5:163-71. [PubMed: 1849605]

22. Newton GL, Arnold K, Price MS, Sherrill C, delCardayre SB, Aharonowitz Y, Cohen G, Davies J, Fahey RC, Davis C. Distribution of thiols in microorganisms: mycothiol is a major thiol in most actinomycetes. J. Bacteriol 1996;178:1990-5. [PubMed: 8606174]

23. Copley SD, Dhillon JK. Lateral gene transfer and parallel evolution in the history of glutathione biosynthesis genes. Genome Biol 2002;3

24. delCardayre SB, Davies JE. Staphylococcus aureus coenzyme A disulfide reductase, a new subfamily of pyridine nucleotide-disulfide oxidoreductase. Sequence, expression, and analysis of cdr. J. Biol. Chem 1998;273:5752-7. [PubMed: 9488708]

25. Luba J, Charrier V, Claiborne A. Coenzyme A-disulfide reductase from Staphylococcus aureus: evidence for asymmetric behavior on interaction with pyridine nucleotides. Biochemistry 1999;38:2725-37. [PubMed: 10052943]

26. Fahey RC, Newton GL. Determination of low-molecular-weight thiols using monobromobimane fluorescent labeling and high-performance liquid chromatography. Methods Enzymol 1987;143:8596. [PubMed: 3657565]

27. Parsonage D, Miller H, Ross RP, Claiborne A. Purification and analysis of streptococcal NADH peroxidase expressed in Escherichia coli. J. Biol. Chem 1993;268:3161-3167. [PubMed: 8428993]

28. Gasteiger, E.; Hoogland, C.; Gattiker, A.; Duvaud, S.; Wilkins, MR.; Appel, RD.; Bairoch, A. Protein identification and analysis tools on the ExPASy server. In: Walker, JM., editor. The Proteomics Protocols Handbook. Humana Press Inc.; Totowa, NJ: 2005. p. 571-607.

29. Studier FW. Protein production by auto-induction in high density shaking cultures. Protein Expr. Purif 2005;41:207-34. [PubMed: 15915565]

30. Calder RB, Williams RS, Ramaswamy G, Rock CO, Campbell E, Unkles SE, Kinghorn JR, Jackowski S. Cloning and characterization of a eukaryotic pantothenate kinase gene (panK) from Aspergillus nidulans. J. Biol. Chem 1999;274:2014-20. [PubMed: 9890959]

31. Pflugrath JW. The finer things in X-ray diffraction data collection. Acta Crystallogr. D Biol. Crystallogr 1999;55:1718-25. [PubMed: 10531521]

32. Terwilliger TC. Maximum-likelihood density modification. Acta Crystallogr. D Biol. Crystallogr 2000;56:965-72. [PubMed: 10944333]

33. Terwilliger TC. Automated main-chain model building by template matching and iterative fragment extension. Acta Crystallogr. D Biol. Crystallogr 2003;59:38-44. [PubMed: 12499537]

34. Terwilliger TC, Berendzen J. Automated MAD and MIR structure solution. Acta Crystallogr. D Biol. Crystallogr 1999;55:849-61. [PubMed: 10089316]

35. Brunger AT, Adams PD, Clore GM, DeLano WL, Gros P, Grosse-Kunstleve RW, Jiang JS, Kuszewski J, Nilges M, Pannu NS, Read RJ, Rice LM, Simonson T, Warren GL. Crystallography \& NMR system: A new software suite for macromolecular structure determination. Acta Crystallogr. D Biol. Crystallogr 1998;54:905-21. [PubMed: 9757107]

36. Emsley P, Cowtan K. Coot: model-building tools for molecular graphics. Acta Crystallogr. D Biol. Crystallogr 2004;60:2126-32. [PubMed: 15572765]

37. Murshudov GN, Vagin AA, Dodson EJ. Refinement of macromolecular structures by the maximumlikelihood method. Acta Crystallogr. D Biol. Crystallogr 1997;53:240-55. [PubMed: 15299926]

38. Lovell SC, Davis IW, Arendall WB 3rd, de Bakker PI, Word JM, Prisant MG, Richardson JS, Richardson DC. Structure validation by $\mathrm{C} \alpha$ geometry: $\varphi, \psi$ and C $\beta$ deviation. Proteins 2003;50:43750. [PubMed: 12557186]

39. Altschul SF, Gish W, Miller W, Myers EW, Lipman DJ. Basic local alignment search tool. J. Mol. Biol 1990;215:403-10. [PubMed: 2231712]

40. Overbeek R, Begley T, Butler RM, Choudhuri JV, Chuang HY, Cohoon M, de Crecy-Lagard V, Diaz N, Disz T, Edwards R, Fonstein M, Frank ED, Gerdes S, Glass EM, Goesmann A, Hanson A, Iwata- 
Reuyl D, Jensen R, Jamshidi N, Krause L, Kubal M, Larsen N, Linke B, McHardy AC, Meyer F, Neuweger H, Olsen G, Olson R, Osterman A, Portnoy V, Pusch GD, Rodionov DA, Ruckert C, Steiner J, Stevens R, Thiele I, Vassieva O, Ye Y, Zagnitko O, Vonstein V. The subsystems approach to genome annotation and its use in the project to annotate 1000 genomes. Nucleic Acids Res 2005;33:5691-702. [PubMed: 16214803]

41. Thompson JD, Higgins DG, Gibson TJ. CLUSTAL W: improving the sensitivity of progressive multiple sequence alignment through sequence weighting, position-specific gap penalties and weight matrix choice. Nucleic Acids Res 1994;22:4673-80. [PubMed: 7984417]

42. Kabsch W, Sander C. Dictionary of protein secondary structure: pattern recognition of hydrogenbonded and geometrical features. Biopolymers 1983;22:2577-637. [PubMed: 6667333]

43. Shindyalov IN, Bourne PE. Protein structure alignment by incremental combinatorial extension (CE) of the optimal path. Protein Eng 1998;11:739-47. [PubMed: 9796821]

44. Holm L, Sander C. Protein structure comparison by alignment of distance matrices. J. Mol. Biol 1993;233:123-38. [PubMed: 8377180]

45. Krissinel E, Henrick K. Secondary-structure matching (SSM), a new tool for fast protein structure alignment in three dimensions. Acta Crystallogr. D Biol. Crystallogr 2004;60:2256-68. [PubMed: 15572779]

46. Peterson JD, Umayam LA, Dickinson T, Hickey EK, White O. The Comprehensive Microbial Resource. Nucleic Acids Res 2001;29:123-5. [PubMed: 11125067]

47. Karplus, PA. Structural flavinology on the brink. In: Ghisla, S.; Kroneck, P.; Macheroux, P.; Sund, H., editors. Flavins and Flavoproteins 1999. Agency for Scientific Publications; Berlin: 1999. p. 233-238.

48. Huang X, Miller W. A time-efficient, linear-space local similarity algorithm. Adv. Appl. Math 1991;12:337-357.

49. Fenton SS, Fahey RC. Analysis of biological thiols: determination of thiol components of disulfides and thioesters. Anal. Biochem 1986;154:34-42. [PubMed: 2939769]

50. Gerdes SY, Scholle MD, D’Souza M, Bernal A, Baev MV, Farrell M, Kurnasov OV, Daugherty MD, Mseeh F, Polanuyer BM, Campbell JW, Anantha S, Shatalin KY, Chowdhury SA, Fonstein MY, Osterman AL. From genetic footprinting to antimicrobial drug targets: examples in cofactor biosynthetic pathways. J. Bacteriol 2002;184:4555-72. [PubMed: 12142426]

51. Flugel RS, Hwangbo Y, Lambalot RH, Cronan JE Jr. Walsh CT. Holo-(acyl carrier protein) synthase and phosphopantetheinyl transfer in Escherichia coli. J. Biol. Chem 2000;275:959-68. [PubMed: 10625633]

52. Choudhry AE, Mandichak TL, Broskey JP, Egolf RW, Kinsland C, Begley TP, Seefeld MA, Ku TW, Brown JR, Zalacain M, Ratnam K. Inhibitors of pantothenate kinase: novel antibiotics for staphylococcal infections. Antimicrob. Agents Chemother 2003;47:2051-5. [PubMed: 12760898]

53. Genschel U. Coenzyme A biosynthesis: reconstruction of the pathway in archaea and an evolutionary scenario based on comparative genomics. Mol. Biol. Evol 2004;21:1242-51. [PubMed: 15014152]

54. Yocum, RR.; Patterson, TA. U.S. Patent 6,830,898. 2004.

55. Read TD, Peterson SN, Tourasse N, Baillie LW, Paulsen IT, Nelson KE, Tettelin H, Fouts DE, Eisen JA, Gill SR, Holtzapple EK, Okstad OA, Helgason E, Rilstone J, Wu M, Kolonay JF, Beanan MJ, Dodson RJ, Brinkac LM, Gwinn M, DeBoy RT, Madpu R, Daugherty SC, Durkin AS, Haft DH, Nelson WC, Peterson JD, Pop M, Khouri HM, Radune D, Benton JL, Mahamoud Y, Jiang L, Hance IR, Weidman JF, Berry KJ, Plaut RD, Wolf AM, Watkins KL, Nierman WC, Hazen A, Cline R, Redmond C, Thwaite JE, White O, Salzberg SL, Thomason B, Friedlander AM, Koehler TM, Hanna PC, Kolsto AB, Fraser CM. The genome sequence of Bacillus anthracis Ames and comparison to closely related bacteria. Nature 2003;423:81-6. [PubMed: 12721629]

56. Bork P, Sander C, Valencia A. An ATPase domain common to prokaryotic cell cycle proteins, sugar kinases, actin, and hsp70 heat shock proteins. Proc. Natl. Acad. Sci. U S A 1992;89:7290-4. [PubMed: 1323828]

57. Rock CO, Park HW, Jackowski S. Role of feedback regulation of pantothenate kinase (CoaA) in control of coenzyme A levels in Escherichia coli. J. Bacteriol 2003;185:3410-5. [PubMed: 12754240] 
58. Setlow B, Setlow P. Levels of acetyl coenzyme A, reduced and oxidized coenzyme A, and coenzyme A in disulfide linkage to protein in dormant and germinated spores and growing and sporulating cells of Bacillus megaterium. J. Bacteriol 1977;132:444-52. [PubMed: 410791]

59. Setlow B, Setlow P. Levels of oxidized and reduced pyridine nucleotides in dormant spores and during growth, sporulation, and spore germination of Bacillus megaterium. J. Bacteriol 1977;129:857-65. [PubMed: 14113]

60. Inglesby TV, O’Toole T, Henderson DA, Bartlett JG, Ascher MS, Eitzen E, Friedlander AM, Gerberding J, Hauer J, Hughes J, McDade J, Osterholm MT, Parker G, Perl TM, Russell PK, Tonat K. Anthrax as a biological weapon, 2002: updated recommendations for management. Jama 2002;287:2236-52. [PubMed: 11980524]

61. Bergman NH, Anderson EC, Swenson EE, Niemeyer MM, Miyoshi AD, Hanna PC. Transcriptional profiling of the Bacillus anthracis life cycle in vitro and an implied model for regulation of spore formation. J. Bacteriol 2006;188:6092-100. [PubMed: 16923876]

62. Liu H, Bergman NH, Thomason B, Shallom S, Hazen A, Crossno J, Rasko DA, Ravel J, Read TD, Peterson SN, Yates J 3rd, Hanna PC. Formation and composition of the Bacillus anthracis endospore. J. Bacteriol 2004;186:164-78. [PubMed: 14679236]

63. Janowiak BE, Griffith OW. Glutathione synthesis in Streptococcus agalactiae. One protein accounts for -glutamylcysteine synthetase and glutathione synthetase activities. J. Biol. Chem 2005;280:11829-39. [PubMed: 15642737]

64. Song WJ, Jackowski S. Cloning, sequencing, and expression of the pantothenate kinase (coaA) gene of Escherichia coli. J. Bacteriol 1992;174:6411-7. [PubMed: 1328157]

65. Markowitz VM, Korzeniewski F, Palaniappan K, Szeto E, Werner G, Padki A, Zhao X, Dubchak I, Hugenholtz P, Anderson I, Lykidis A, Mavromatis K, Ivanova N, Kyrpides NC. The integrated microbial genomes (IMG) system. Nucleic Acids Res 2006;34:D344-8. [PubMed: 16381883]

66. Baker LM, Raudonikiene A, Hoffman PS, Poole LB. Essential thioredoxin-dependent peroxiredoxin system from Helicobacter pylori: genetic and kinetic characterization. J. Bacteriol 2001;183:196173. [PubMed: 11222594] 


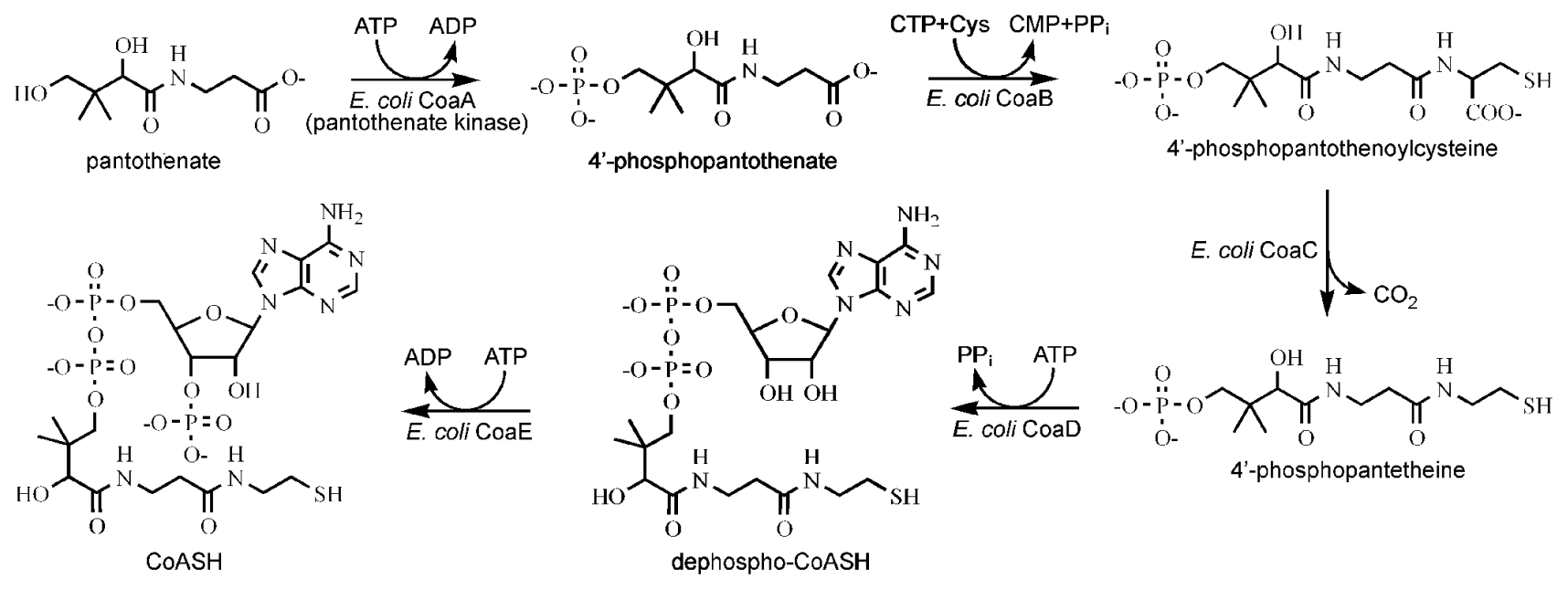

Scheme 1.

Pathway for CoASH Biosynthesis in E. coli; coaBC Encodes a Single Bifunctional Polypeptide. 


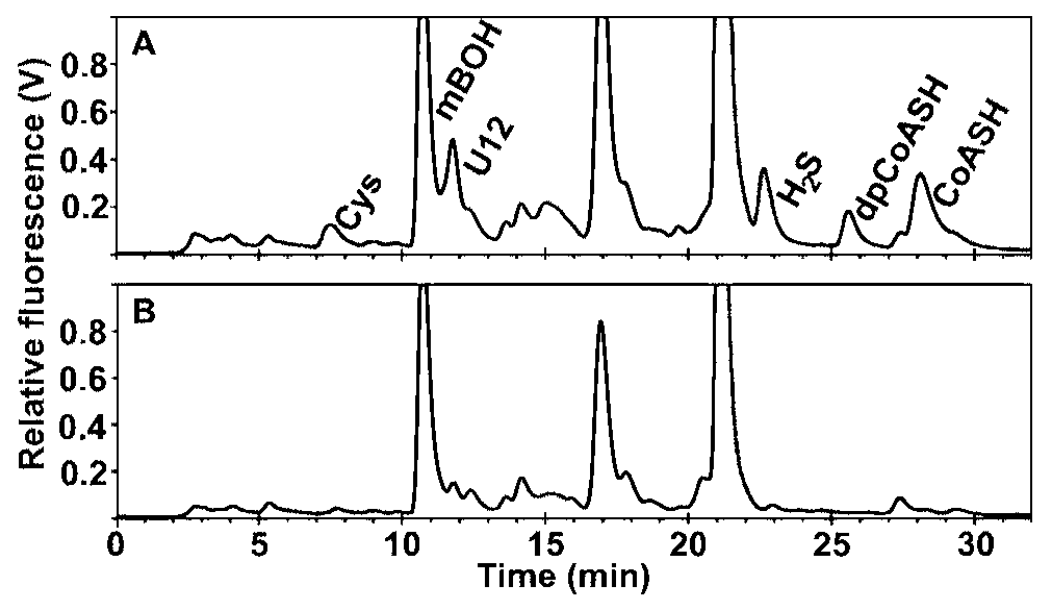

Figure 1.

Reverse phase HPLC of $B$. anthracis thiols. The two chromatograms correspond to the thiol sample (A), in which cell extracts were reacted with $\mathrm{mBBr}$, and the control sample (B), in which cell extracts were reacted first with NEM and then with $\mathrm{mBBr}$. Peaks that appear in the thiol sample but not the control sample are bimane derivatives of cellular thiols. $\mathrm{mBOH}$, hydrolysis product of $\mathrm{mBBr}$; $\mathrm{U} 12$, unidentified $B$. anthracis thiol (bimane derivative) eluting at 12 min in HPLC protocols 1 and 2. 


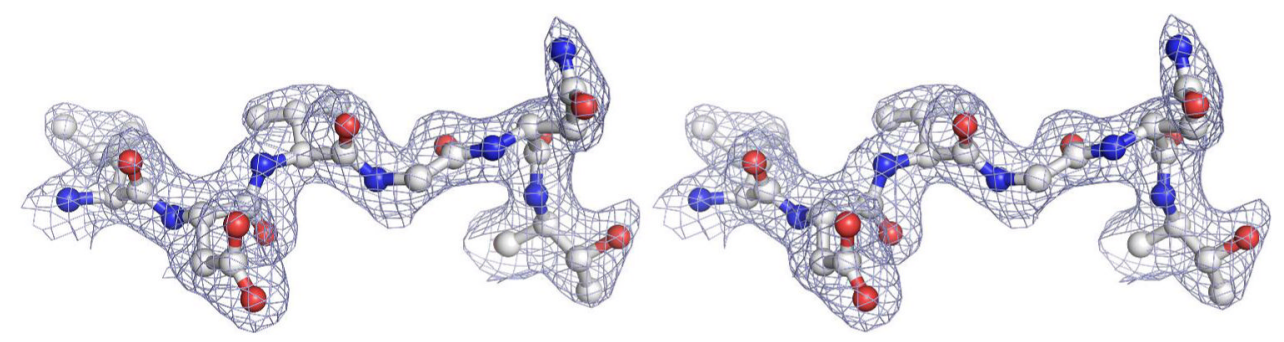

Figure 2.

Final $2 F_{\mathrm{o}}-F_{\mathrm{c}}$ map, in stereo, for residues Leu5-Thr10 of the PHOSPHATE1 motif, together with the refined model. All residues are color-coded by atom type. The depicted contour level is $1 \sigma$. 

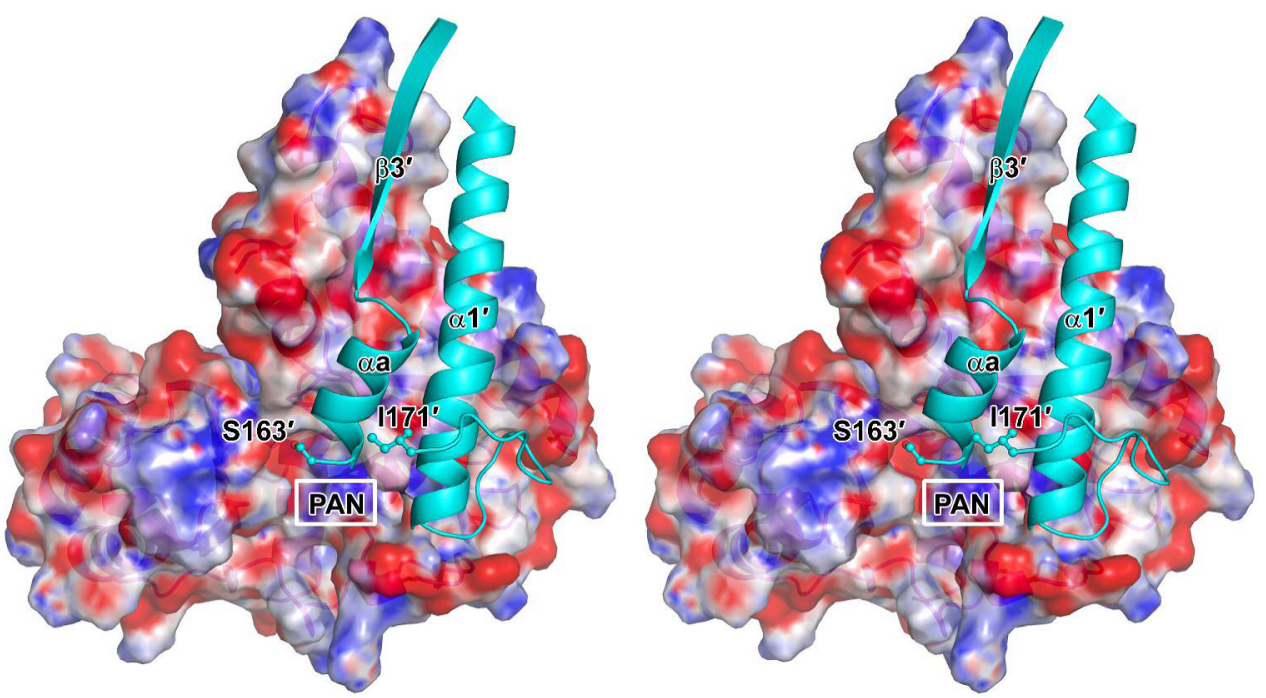

Figure 3.

Elements involved in $\mathrm{Ba}$ PanK dimerization, in stereo. Prime symbols designate secondary structural units in domain II [of monomer B (cyan), in this case]; lettered designations (e.g., $\alpha$ a) indicate insertions relative to the shared core fold. These monomer B elements are overlaid with a surface representation (color-coded by electrostatic potential) of monomer $\mathrm{A}$. The segment $164^{\prime}-170^{\prime}$ missing electron density in monomer B is part of the long loop (163'-183') connecting $\alpha \mathrm{a}$ and $\alpha 1^{\prime}$ in an area above the monomer A Pan-binding pocket. 


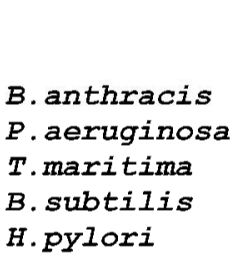

$B$. anthracis

$P$. aeruginosa

T.maritima

B. subtilis

H.pylori
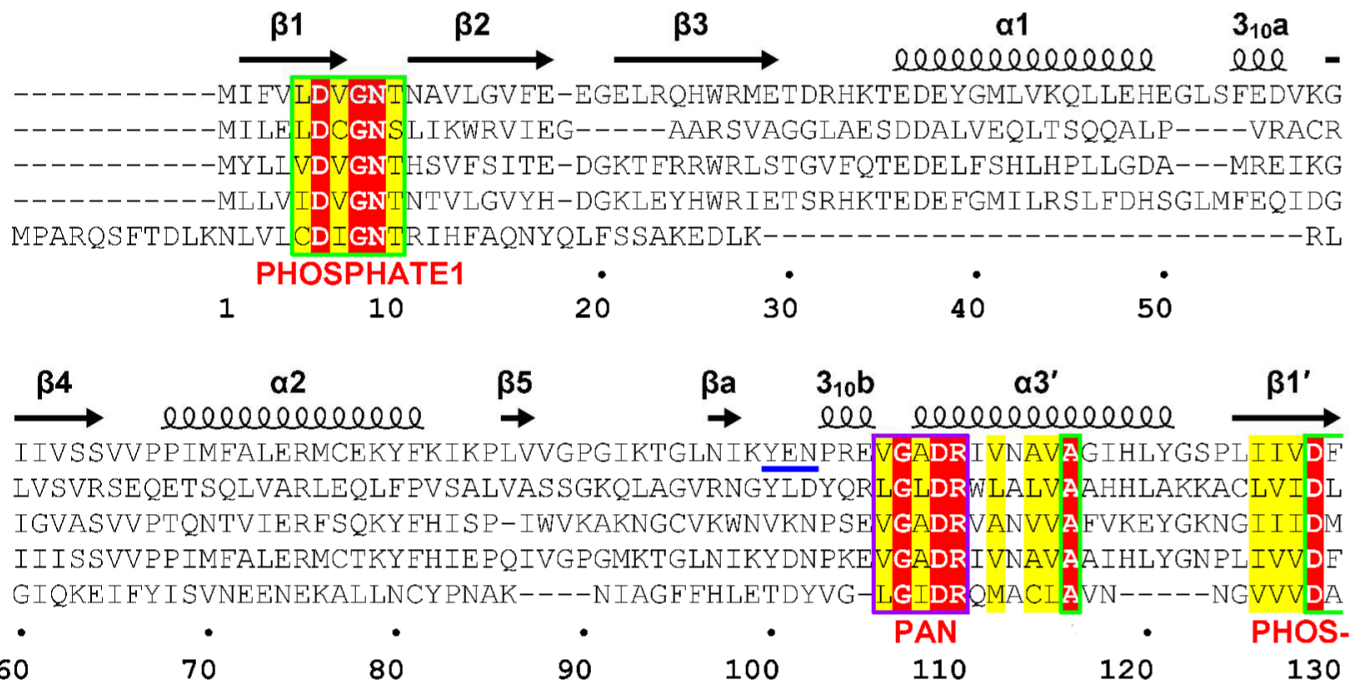

$\beta 2^{\prime}$

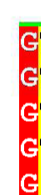 \\ G}

B. anthracis
P. aeruginosa
T.maritima
B. subtilis
H.pylori

80

B3'

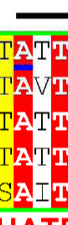

Y YCY

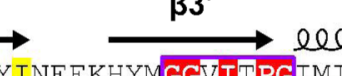

00

aa

100

110

120

$\alpha 1^{\prime}$

作

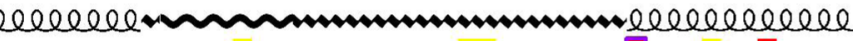

VDLVVN-GSYEGGAILPGEFMMVHSLFRGTAKL PLVE-VKPADFVV----GKDTEENIRLEVVNG

YCY I DENKQYMGGAIAPGITISTEALYSRAAKLPRIE-ITRPDNI I----GKNTVSAMQSEILFG

IDLIKE-GKHLGGCILPGLAQYIHAYKKSAKILEQPFKALDSLEVL----PKSTRDAVNYGMVLS
PHATE

140

INTERF
150

160

"PAN CAP"

190

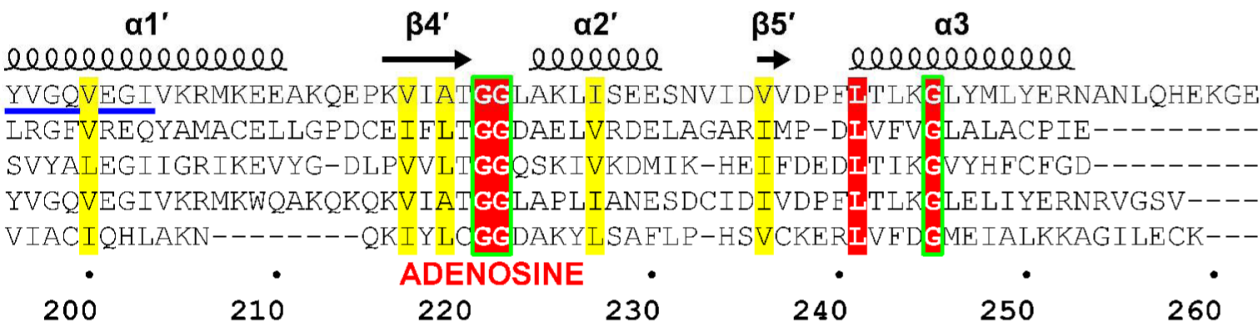

Figure 4.

Structure-based sequence alignment for $B a$ PanK and four known functional type III PanKs (references given in the text). Structures have now been determined for $B a$ PanK (this work), $P a$ PanK (19), and $T m P a n K ~(20)$. Residue numbering and assignments correspond to $B a P a n K$ and include the 164-170 segment ( $\sim$ ) for which electron density is absent. This segment constitutes a part of the loop (extending through Asn 183; $M$ ) that exhibits different conformations in the three structures. Red and yellow blocks correspond to conserved residues and conservative substitutions, respectively. ASKHA motifs are highlighted in green boxes (Ala116 and Gly245 represent CONNECT1 and CONNECT2 elements), and the new PAN and INTERFACE motifs, as well as Thr184, are highlighted in magenta boxes. Blue underscores represent residues involved in direct contacts across the dimer interface. 


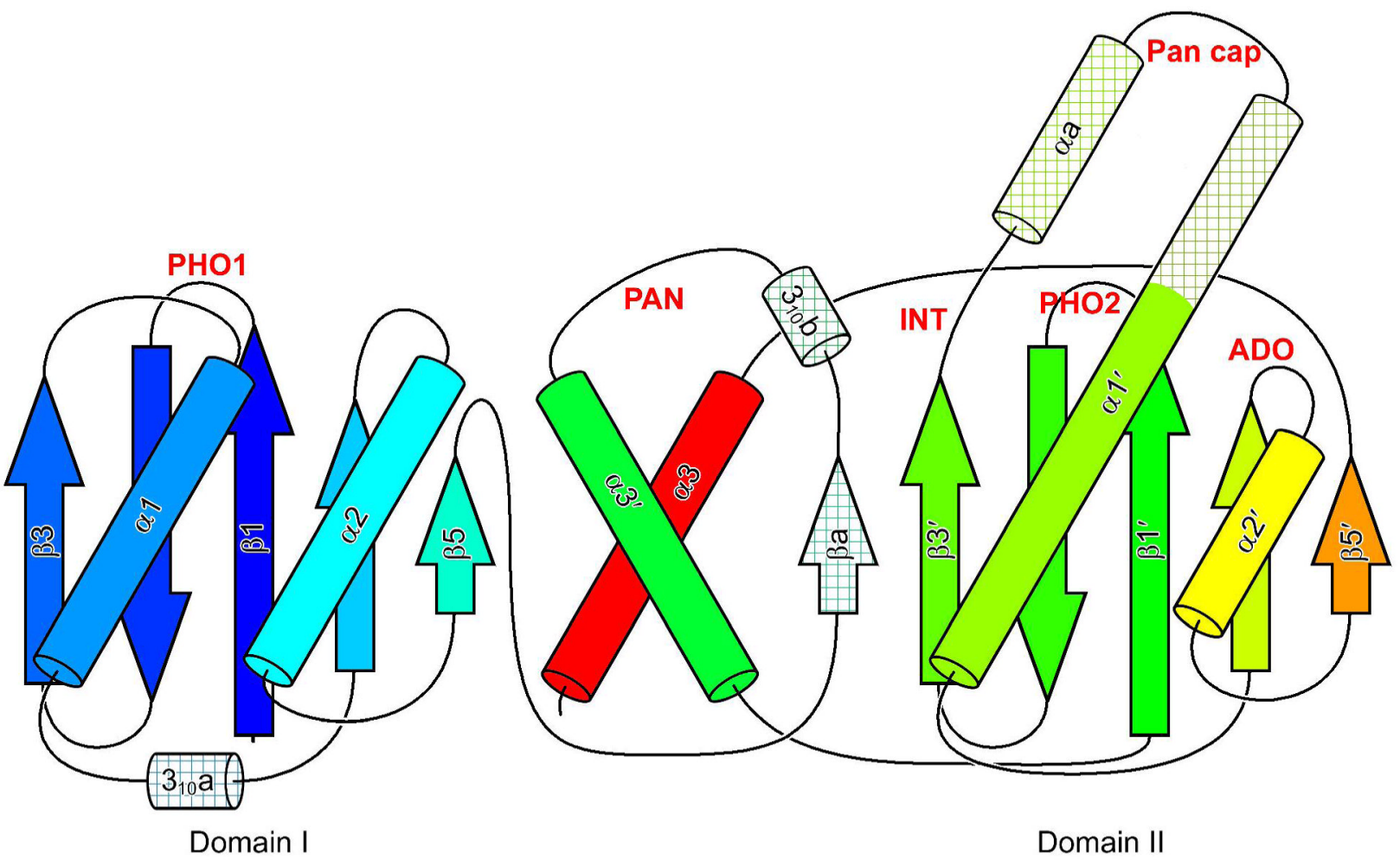

Figure 5.

Topology diagram for the $B a \mathrm{PanK}$ monomer. Domains I and II represent an internal duplication of the RNase $\mathrm{H}$-like fold, and helices $\alpha 3$ and $\alpha 3^{\prime}$ cross over to form the base of an interdomain cleft. Insertions to the core ASKHA fold are hatched; motifs indicated in Figure 4 are labeled in red (PHO, PHOSPHATE; INT, INTERFACE; ADO, ADENOSINE), as is the Pan cap segment. The diagram is represented as a rainbow from blue ( $\mathrm{N}$-terminus) to red (C-terminus). 


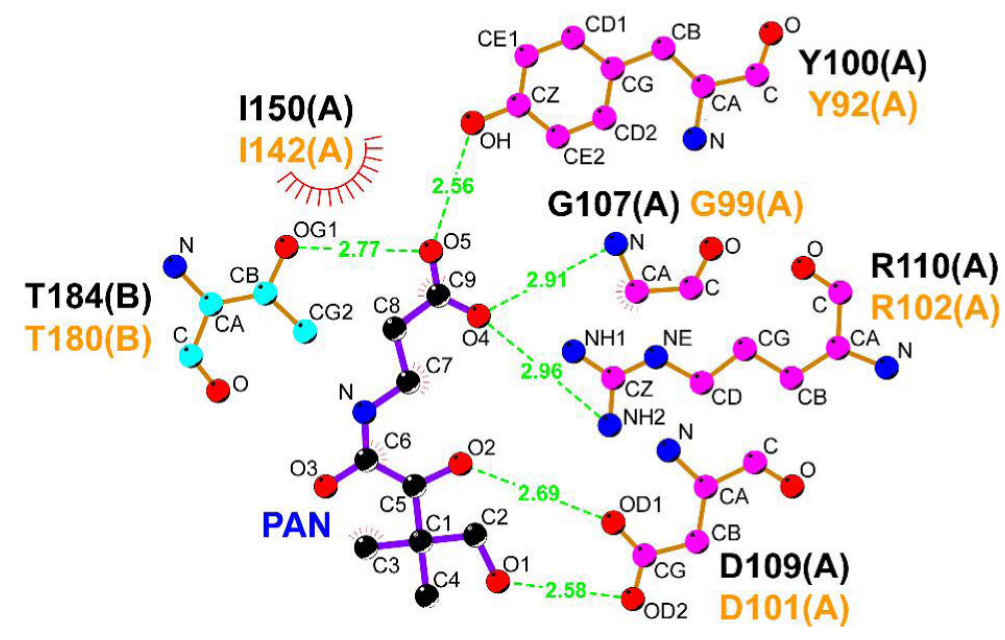

Figure 6.

LIGPLOT representation of protein interactions with Pan in the PaPanK-Pan complex (amino acid residues labeled in orange; equivalent $B a$ PanK residues in black), using default parameters for geometry and hydrogen-bonding distance. Carbon atoms for monomer A residues are colored magenta, while those for Thr180' (monomer B) are in cyan. Pan is color-coded by atom type, with carbon atoms in black; note that Pan atom numbering here follows that for the bound Pan ("DPA") in the Protein Data Bank file 2F9W. 

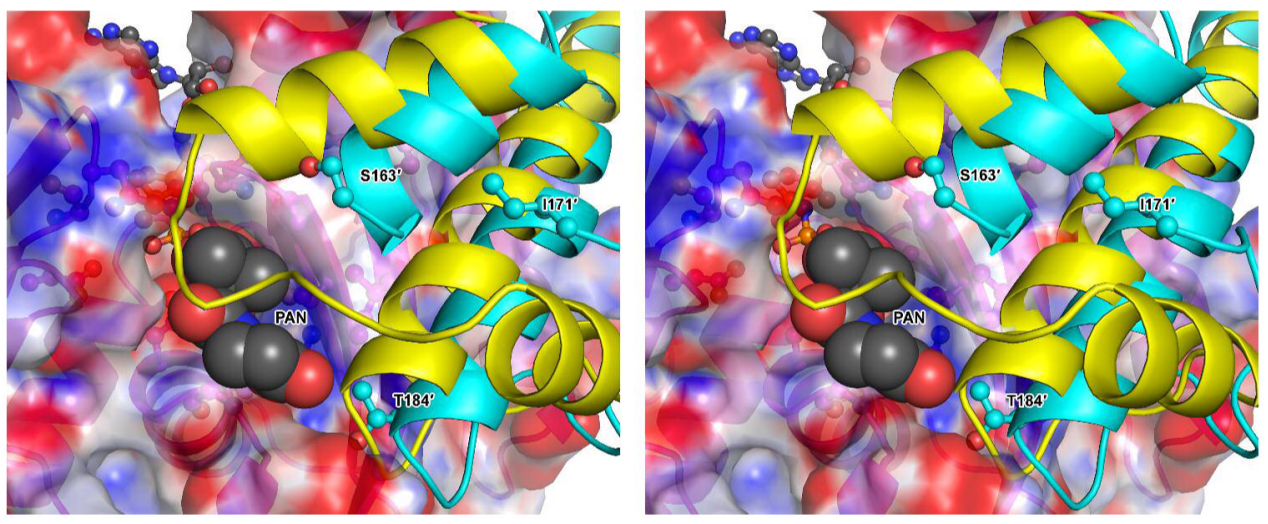

Figure 7.

Ordered versus disordered Pan caps in $\mathrm{PaPanK}$ and $\mathrm{BaPanK}$ (stereo). The $\alpha \mathrm{a}$ and $\alpha 1^{\prime}$ helices of the $B a$ PanK-Pan model (cyan) are overlaid with a surface rendering (color-coded by electrostatic potential) of the Pan-binding pocket of monomer A. Bound Pan is represented with a space-filling model. Bound ATP is also shown, as modeled based on the structure of the type II SaPanK-AMPPNP complex. The $\alpha$ a and $\alpha 1^{\prime}$ helices of $P a$ PanK monomer B (Pan complex, in yellow), with the Leu153'-Pro176' loop, are shown from a superposition. 
Table 1

Data Collection and Phasing Statistics

\begin{tabular}{llll}
\hline & \multicolumn{1}{c}{ edge $^{\boldsymbol{a}}$} & \multicolumn{1}{c}{ peak $^{\boldsymbol{a}}$} & remote $^{\boldsymbol{a}}$ \\
\hline Wavelength $(\AA)$ & 0.9801 & 0.9797 & 0.9500 \\
Resolution range $(\AA)$ & $44.5-2.0(2.1-2.0)^{b}$ & $44.5-2.0(2.1-2.0)$ & $44.5-2.1(2.2-2.1)$ \\
Reflections & 182,091 & 181,828 & 160,764 \\
Unique reflections & 26,148 & 26,073 & 22,673 \\
Completeness $(\%)$ & $100(100)$ & $100(100)$ & $100(100)$ \\
Cell $(\AA)$ & 67.9133 .541 .2 & 67.9133 .441 .1 & 67.9133 .641 .2 \\
Cell $\left({ }^{\circ}\right)$ & 909090 & 909090 & 909090 \\
Redundancy & $7.0(5.8)$ & $7.0(5.8)$ & $7.1(7.3)$ \\
$\mathrm{R}_{\text {merge }}$ & $0.04(0.31)$ & $0.06(0.33)$ & $0.05(0.29)$ \\
I/ $\sigma$ & $20.3(5.7)$ & $16.0(4.8)$ & $14.9(4.7)$ \\
Figure of merit & 0.51 & - & - \\
\hline
\end{tabular}

${ }^{a}$ Collected at beamline X12C of the National Synchrotron Light Source (Brookhaven National Laboratory) using an ADSC Q210 CCD detector.

${ }^{b}$ Values in parentheses are for the highest resolution shell. 


\section{Table 2}

Crystallographic Refinement Statistics

\begin{tabular}{lc}
\hline Resolution range $(\AA)$ & $35.2-2.0(2.1-2.0)^{a}$ \\
Number of reflections total & $26,020(1,910)$ \\
Number of reflections in work set & $24,696(1,822)$ \\
Number of reflections in test set & $1,324(88)$ \\
Amplitude cutoff $b$ & 0 \\
$R$-factor $(\%)$ & $21.5(24.6)$ \\
$R$-free $(\%)$ & $25.8(31.2)$ \\
Number of amino acid residues & 247 \\
Number of water molecules & 180 \\
Number of other molecules $c$ & 1 \\
Number of total non-hydrogen atoms & 2,121 \\
Average $B$-factor $\left(\AA{ }^{2}\right)$ & 40.9 \\
Stereochemical ideality & \\
$\quad$ bond length rmsd $(\AA)$ & 0.02 \\
$\quad$ bond angle rmsd $\left({ }^{\circ}\right)$ & 1.61 \\
$\quad \psi$;avored $(\%)$ & 98.4 \\
$\quad \psi$ allowed $(\%)$ & 100
\end{tabular}

${ }^{a}$ Values in parentheses are for the highest resolution shell.

${ }^{b}$ Refined against all data in the resolution range.

${ }^{c}$ Ethylene glycol. 
Table 3

Codistribution of CoASH-refractory PanKs and CoADR-like Proteins in Bacteria. ${ }^{a}$

\begin{tabular}{|c|c|}
\hline Bacillus anthracis $b, c$ & Oceanobacillus iheyensis $b$ \\
\hline Bacillus cereus ${ }^{b, c}$ & Pelobacter carbinolicus \\
\hline Bacillus clausii $^{d}$ & Rhodospirillum rubrum \\
\hline Bacillus halodurans $^{d}$ & Staphylococcus aureus ${ }^{c, g}$ \\
\hline Bacillus megaterium $^{e}$ & Staphylococcus epidermidis ${ }^{g}$ \\
\hline Bacteroides thetaiotamicron ${ }^{f}$ & Staphylococcus haemolyticus ${ }^{g}$ \\
\hline Borrelia burgdorferi $f$ & Staphylococcus saprophyticus ${ }^{g}$ \\
\hline Borrelia garinii $f^{\prime}$ & Streptomyces avermitilis $d, h$ \\
\hline Clostridium tetani & Streptomyces coelicolor ${ }^{d, h}$ \\
\hline Deinococcus radiodurans ${ }^{c}$ & Symbiobacterium thermophilum \\
\hline Fusobacterium nucleatum & Thermoanaerobacter tengcongensis \\
\hline Geobacillus kaustophilus & Thermotoga maritima \\
\hline Geobacter sulfurreducens & Thermus thermophilus \\
\hline Nocardia farcinica $d$ & \\
\hline
\end{tabular}

${ }^{a}$ Analyzed with TIGR-Comprehensive Microbial Resource as described in "Experimental Procedures."

${ }^{b}$ Contains homologs to both type II and III PanKs.

${ }^{c}$ Known to lack GSH and to contain CoASH as major low-molecular weight thiol.

$d_{\text {Contains homologs to both type I and III PanKs. }}$

$e_{\text {J. Ravel, personal communication. }}$

$f_{\text {Ref. (20). }}$

${ }^{g}$ Contains only type II PanK.

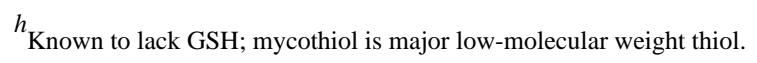

